\title{
Contributions of Different Modes of TRPV1 Activation to TRPV1 Antagonist-Induced Hyperthermia
}

\author{
Andras Garami, ${ }^{1}$ Yury P. Shimansky, ${ }^{2}$ Eszter Pakai, ${ }^{1}$ Daniela L. Oliveira, ${ }^{1}$ Narender R. Gavva, ${ }^{3}$ \\ and Andrej A. Romanovsky ${ }^{1}$ \\ ${ }^{1}$ Systemic Inflammation Laboratory, Trauma Research, St. Joseph's Hospital and Medical Center, Phoenix, Arizona 85013, ${ }^{2}$ Harrington Department of \\ Bioengineering, Arizona State University, Tempe, Arizona 85287, and ${ }^{3}$ Department of Neuroscience, Amgen, Thousand Oaks, California 91320
}

Transient receptor potential vanilloid-1 (TRPV1) antagonists are widely viewed as next-generation pain therapeutics. However, these compounds cause hyperthermia, a serious side effect. TRPV1 antagonists differentially block three modes of TRPV1 activation: by heat, protons, and chemical ligands (e.g., capsaicin). We asked what combination of potencies in these three modes of TRPV1 activation corresponds to the lowest potency of a TRPV1 antagonist to cause hyperthermia. We studied hyperthermic responses of rats, mice, and guinea pigs to eight TRPV1 antagonists with different pharmacological profiles and used mathematical modeling to find a relative contribution of the blockade of each activation mode to the development of hyperthermia. We found that the hyperthermic effect has the highest sensitivity to the extent of TRPV1 blockade in the proton mode $(0.43$ to 0.65$)$ with no to moderate sensitivity in the capsaicin mode $(-0.01$ to 0.34$)$ and no sensitivity in the heat mode $(0.00$ to 0.01$)$. We conclude that hyperthermia-free TRPV1 antagonists do not block TRPV1 activation by protons, even if they are potent blockers of the heat mode, and that decreasing the potency to block the capsaicin mode may further decrease the potency to cause hyperthermia.

\section{Introduction}

The transient receptor potential vanilloid-1 (TRPV1) channel is abundant in primary afferent neurons innervating both the skin and the internal organs (Caterina et al., 1997; Sugiura et al., 2007). The TRPV1 channel can be activated through three main mechanisms: by heat, protons, and chemical ligands such as capsaicin (CAP) (Caterina et al., 1997; Jordt et al., 2000). Because blocking the TRPV1 channel causes analgesia in several animal models (Gavva et al., 2005; Ghilardi et al., 2005; Honore et al., 2009), TRPV1 antagonists are widely viewed as next-generation pain therapeutics (for review, see Romanovsky et al., 2009). However, many new, highly selective TRPV1 antagonists of different chemotypes cause hyperthermia, an undesired, on-target side effect, in laboratory animals (Gavva et al., 2007a,b, 2008; Steiner et al., 2007; Lehto et al., 2008; Honore et al., 2009) and human patients (Gavva et al., 2008). Of several strategies proposed to overcome this side effect, one is based on the assumption that the potency of an antagonist to cause hyperthermia may correlate with its potency to block a certain mode (or modes) of TRPV1 activation (for review, see Romanovsky et al., 2009). For example, Lehto et al. (2008) have found that several doses of AMG8562, an antagonist that potentiates proton activation of the rat TRPV1 in vitro, do not cause hyperthermia (but cause

\footnotetext{
Received 0ct. 14, 2009; revised Dec. 7, 2009; accepted Dec. 9, 2009.

This research has been supported in part by the National Institutes of Health (Grant R01NS41233 to A.A.R.) and Amgen, Inc. (study agreements with St. Joseph's Hospital).

Correspondence should be addressed to Dr. Andrej A. Romanovsky, Systemic Inflammation Laboratory, Trauma Research, St. Joseph's Hospital and Medical Center, 350 West Thomas Road, Phoenix, AZ 85013. E-mail: aromano@chw.edu.

D0I:10.1523/JNEUROSC1.5150-09.2010

Copyright $\odot 2010$ the authors $\quad 0270-6474 / 10 / 301435-06 \$ 15.00 / 0$
}

hypothermia) in rats. However, to what extent the ability of an antagonist to block TRPV1 activation in each mode (viz., by heat, protons, or CAP) contributes to the hyperthermic response is unknown, and a general rule for identifying hyperthermia-free TRPV1 antagonists based on standard activity tests in vitro does not exist.

Finding quantitative contributions of the blockade of each mode of TRPV1 activation to the hyperthermic response was the aim of the present study. The study consisted of a series of pharmacological experiments, a comparative physiology analysis, and mathematical modeling. In the pharmacological experiments, we studied eight TRPV1 antagonists with different potencies to block the activation of the rat TRPV1 channel by heat, protons, and CAP (Table 1). We established dose-response curves for the hyperthermic effect of these drugs and analyzed these curves graphically to compare the potency of TRPV1 antagonists to cause hyperthermia with their potency to block TRPV1 activation in each mode. In the comparative analysis, we studied the thermal effect of the same TRPV1 antagonist (capsazepine, CPZ) in two mammalian species with different TRPV1 channels: rats and guinea pigs. CPZ is reasonably potent in inhibiting the proton activation of TRPV1 in guinea pigs (Savidge et al., 2002), but not in rats (Gavva et al., 2005). Finally, we developed a mathematical model and fit the data obtained in the pharmacological experiments into the model to determine quantitative contributions of different modes of TRPV1 activation to TRPV1 antagonistinduced hyperthermia.

\section{Materials and Methods}

Animals. One hundred ninety-four adult male Wistar rats (Harlan), 15 adult male mice with or without a homozygous targeted null mutation of the Trpv1 gene (Trpv1 $1^{-/-}$and $\operatorname{Tr} p v 1^{+/+}$, respectively) (Amgen colony at Charles River Laboratories), and 14 adult male guinea pigs (Charles River 
Table 1. TRPV1 antagonists: their potencies to block the activation of the rat TRPV1 channel in different modes

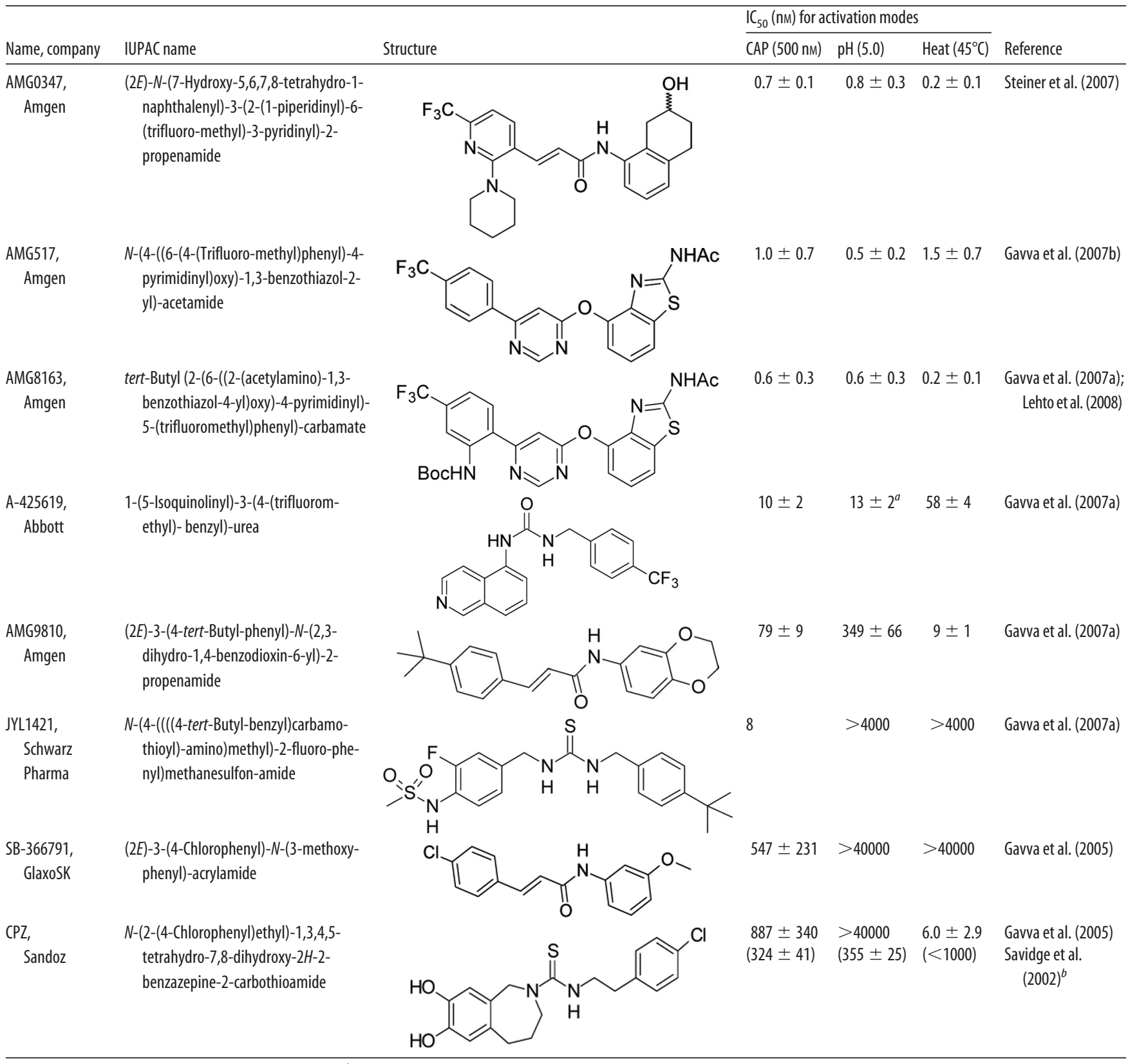

${ }^{a}$ This value was measured at a $\mathrm{pH}$ of 5.5 (no inhibition occurred at 5.0 ). ${ }^{b}$ For comparison, the $\mathrm{IC}_{50}$ values for guinea pig TRPV1 are shown in parentheses (measured at a $\mathrm{CAP}$ concentration of $100 \mathrm{~nm}, \mathrm{pH}$ of 5.5 , and temperature of $50^{\circ} \mathrm{C}$ ).

Laboratories) were housed individually at a $12 \mathrm{~h}$ light/dark cycle (lights on at 6:00 A.M.). Standard rodent chow and tap water were available ad libitum. All animals were extensively habituated to experimental setups. All protocols were approved by the St. Joseph's Hospital Animal Care and Use Committee.

Surgeries. For drug delivery, each rat or guinea pig was implanted with an intravenous catheter, and each mouse with an intraperitoneal catheter. During the same surgery, each guinea pig and mouse was also implanted with a miniature datalogger (Subcue Dataloggers) for recording abdominal temperature. All procedures involved have been described previously (Rudaya et al., 2005; Steiner et al., 2007, 2009).

Experimental setups. Pharmacological experiments in rats were conducted in a thermocouple thermometry setup (Steiner et al., 2007), where colonic $\left(T_{c}\right)$ and tail skin temperatures were recorded with copperconstantan thermocouples fed into a data logger (Cole-Parmer). $T_{\mathrm{c}}$ was used as a measure of deep body temperature; skin temperature was used to calculate the heat loss index, a measure of the tone of tail skin vasculature (see supplemental Materials and Methods, available at www.jneurosci.org as supplemental material). A separate series of experiments was conducted in a respirometry setup (Steiner et al., 2007), where, in addition to the two temperatures, the rate of oxygen consumption (measure of thermogenesis) was recorded by a multichannel respirometer (Sable Systems). In either setup, the rats were loosely restrained with individual confiners and kept inside a climatic chamber (model 3940; Forma Scientific). Unrestrained mice (each in its home cage) and restrained guinea pigs were used in the same climatic chamber; the abdominal temperature was recorded with Subcue dataloggers, and no thermoeffector activity was monitored. The exteriorized end of an intravenous or intraperitoneal catheter was connected to a syringe filled with a drug of interest and placed in an infusion pump (Stoelting), thus allowing the drug to be administered without disturbing the animal. Experiments in each species were conducted under their thermoneutral conditions (Romanovsky et al., 2002) verified by infrared thermography for each setup.

Drugs. The TRPV1 antagonists used (Table 1) were synthesized by Amgen. Six different vehicles were used to deliver these compounds; the total number of treatments (different doses of antagonists and vehicles) studied was 49 (supplemental Materials and Methods, available at www. jneurosci.org as supplemental material). 


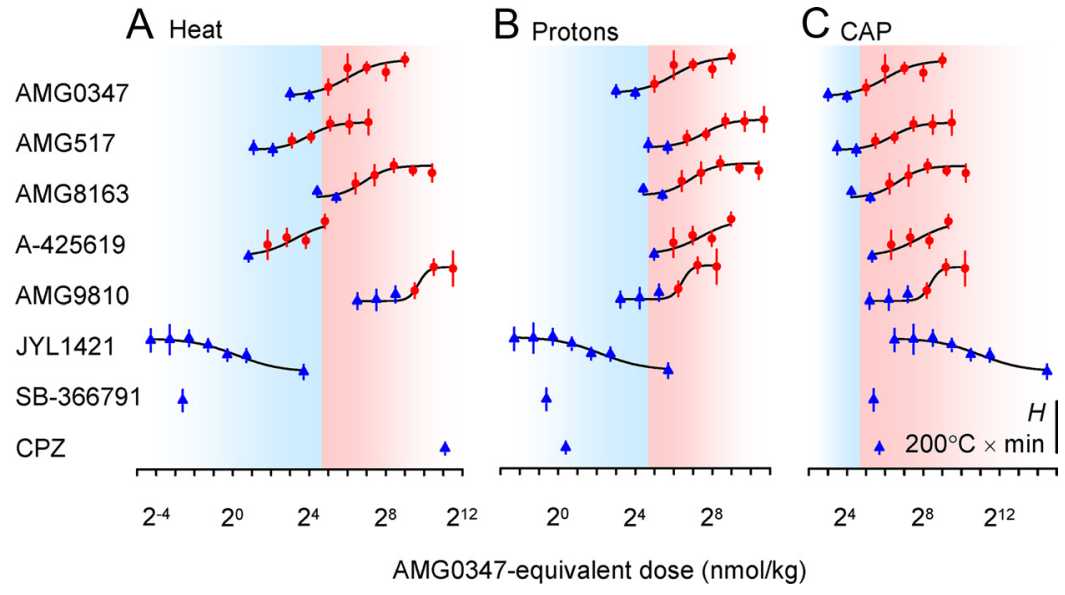

Figure 1. The dose dependence of the hyperthermic effect $H$ of TRPV1 antagonists. $A-C$, Doses of each antagonist are expressed as doses of AMG0347 needed to equipotently block TRPV1 activation in the heat $(\boldsymbol{A})$, proton (B), or CAP (C) mode (see Materials and Methods, Data processing and analysis). If the potency of TRPV1 antagonists to cause hyperthermia is determined by their potency to block a certain mode of TRPV1 activation, the panel corresponding to this mode of activation should have all red symbols located on the red background, and all blue symbols on the blue background.

Data processing and analysis. The data processing algorithm for body temperature data is depicted in supplemental Figure 1 (available at www. jneurosci.org as supplemental material) using the response to AMG517 as an example. Individual $T_{\mathrm{c}}$ curves and effector responses to AMG517 $(256 \mathrm{nmol} / \mathrm{kg}$ ) or its vehicle are shown in supplemental Figure $1 A$ (available at www.jneurosci.org as supplemental material). From individual $T_{c}$ curves, a mean $( \pm \mathrm{SE}) T_{\mathrm{c}}$ curve was calculated for each dose of AMG517 and for its vehicle. The mean $T_{\mathrm{c}}$ curve for the response to the vehicle was then subtracted from the mean $T_{\mathrm{c}}$ curve for the response to each dose of AMG517, as shown for the $256 \mathrm{nmol} / \mathrm{kg}$ dose administered to rats (supplemental Fig. $1 B$, available at www.jneurosci.org as supplemental material). Each mean $T_{\mathrm{c}}$ difference curve was then integrated over $0-180$ min to give a hyperthermic response $H$ value $\left({ }^{\circ} \mathrm{C} \times \min \right)$, and the $H$ values were used to determine the dose dependence of the hyperthermic response to AMG517 (supplemental Fig. $1 D$, available at www.jneurosci. org as supplemental material). The $H$ values for all antagonists used are reported in supplemental Table 1 (available at www.jneurosci.org as supplemental material). The deep body temperature and effector responses were compared by two-way ANOVA with post hoc comparisons (Statistica AX'99, Statsoft).

To quantify the contributions of the blockade of each mode of TRPV1 activation to the hyperthermic effect, the $H$ values were fit into a mathematical model (see supplemental Model, available at www.jneurosci.org as supplemental material). The model used a sigmoid nonlinearity to describe the dependence of the hyperthermic response $H$ on the dose of an antagonist and expressed the interaction among the three modes of TRPV1 activation as a weighted sum, where each weight was proportional to the relative sensitivity $k$ of the response $H$ to the extent of TRPV1 blockade in the corresponding mode. After the $k$ values for all modes were found, they were subjected to a statistical analysis using a MonteCarlo simulation technique.

\section{Results}

\section{Pharmacological experiments: AMG517 causes an on-target hyperthermic effect}

The thermoregulatory effect of AMG517, the antagonist used in clinical trials (Gavva et al., 2008), was characterized in more detail. In rats, AMG517 caused dose-dependent hyperthermia at doses $>16 \mathrm{nmol} / \mathrm{kg}$, with a saturation of the response occurring at doses $>256 \mathrm{nmol} / \mathrm{kg}$ (supplemental Fig. $1 D$, available at www. jneurosci.org as supplemental material). At $256 \mathrm{nmol} / \mathrm{kg}$, AMG517 caused a moderate increase in $T_{c}\left(0.7 \pm 0.1^{\circ} \mathrm{C}, p<0.0001\right)$ preceded by tail skin vasoconstriction and activation of thermogenesis (supplemental Fig. $1 B, C$, available at www.jneurosci.org as supplemental material). We also studied the response to the same dose of AMG517 (but administered intraperitoneally) in $\operatorname{Tr} p v 1^{-1-}$ mice. Whereas the hyperthermic response of $\operatorname{Trp} v 1^{+/+}$mice to AMG517 was similar to that of rats $(0.7 \pm$ $\left.0.3^{\circ} \mathrm{C}, p<0.0001\right), \operatorname{Tr} p v 1^{-1-}$ mice were thermally insensitive to AMG517 (supplemental Fig. 1C, available at www. jneurosci.org as supplemental material). Hence, AMG517 is the second TRPV1 antagonist shown to cause hyperthermia by acting on the TRPV1 channel. That TRPV1 antagonist-induced hyperthermia is an on-target effect was first shown for AMG0347 (Steiner et al., 2007).

\section{Pharmacological experiments: antagonism of proton activation is important for the development of hyperthermia}

As in the past (Steiner et al., 2007), AMG0347 caused hyperthermia at 32-512 nmol/kg. AMG8163, A-425619, and AMG9810 caused hyperthermia in the following dose ranges: $64-1024,1024-8192$, and 32,768-131,072 nmol/ $\mathrm{kg}$, respectively. SB-366791 and CPZ were administered each at the highest feasible dose $(32,768$ and $65,536 \mathrm{nmol} / \mathrm{kg}$, respectively) and caused no significant changes in $T_{c}$ in rats. In agreement with previous studies (Suh et al., 2003; Gavva et al., 2007a), JYL1421 was thermally ineffective in a wide dose range (1024$32,768 \mathrm{nmol} / \mathrm{kg}$ ). However, at higher doses, JYL1421 caused hypothermia, which is a novel observation.

The values of the temperature response $H$ determined in the pharmacological experiments (supplemental Table 1, available at www.jneurosci.org as supplemental material) were analyzed graphically to find whether the potency of TRPV1 antagonists to cause hyperthermia in vivo better corresponds to their potency to block TRPV1 activation by heat (Fig. $1 A$ ), protons (Fig. $1 B$ ), or CAP (Fig. 1C) in vitro. Doses of each antagonist were expressed as doses of AMG0347 (the antagonist most studied by our group) needed to equipotently block TRPV1 activation in the corresponding mode. For this, each dose of each antagonist was multiplied by a ratio between the $\mathrm{IC}_{50}$ value for AMG0347 (numerator) and the $\mathrm{IC}_{50}$ value for the antagonist of interest (denominator) in the same activation mode. All $\mathrm{IC}_{50}$ values used were determined in our recent studies (Table 1). In each panel, the dose range at which AMG0347 caused hyperthermia is shown in a red background; the dose range at which AMG0347 did not cause hyperthermia is shown in a blue background. For each antagonist, positive $H$ values are shown as red circles; negative and near-zero values are shown as blue triangles. If the potency of TRPV1 antagonists to cause hyperthermia is determined by their potency to block a certain mode of TRPV1 activation (e.g., by heat), then in the corresponding panel (in our example, Fig. $1 \mathrm{~A}$, heat), all red symbols should be located on the red background, and all blue symbols on the blue background. We found that the proton mode was the closest to this ideal situation: only five blue triangles "trespassed" into the red area, but even those were located close to the borderline (Fig. $1 B$ ). There were at least twice as many nonconforming symbols in either the heat mode (Fig. 1A) or CAP mode (Fig. 1C). 
A Guinea pigs, means $\pm S E$

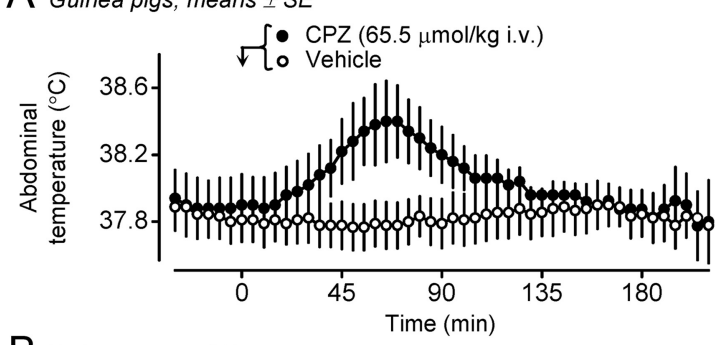

B Rats, means $\pm S E$
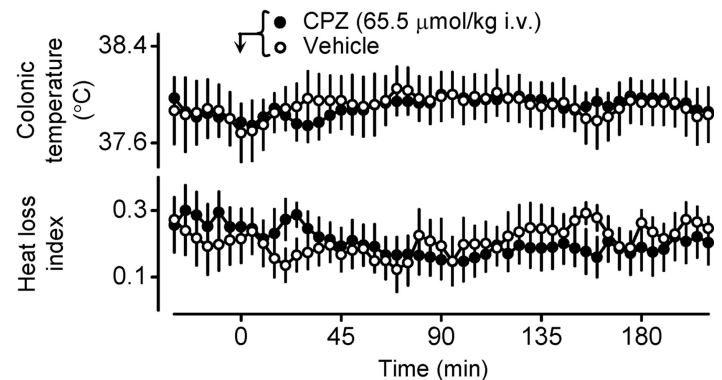

Figure 2. $\quad \boldsymbol{A}, \boldsymbol{B}$, The thermoregulatory effect of $\mathrm{CPZ}$ in guinea pigs $(\boldsymbol{A})$ and rats $(\boldsymbol{B})$. Guinea pigs readily respond with hyperthermia to $C P Z$ (dose indicated; $n=5$ ), but not to its vehicle $(n=9)$. Administration of the same dose of CPZ or its vehicle to rats ( $n=8$ in each group) causes no significant changes in either $T_{\mathrm{c}}$ (top) or the heat loss index (bottom).

\section{Comparative analysis: confirmation of the importance of the proton mode}

If our hypothesis that blocking the proton mode is important for the development of hyperthermia is correct, guinea pigs should be much more sensitive to the hyperthermic action of CPZ than rats, because CPZ does not block TRPV1 activation in the proton mode in the rat $\left(\mathrm{IC}_{50}>40,000 \mathrm{nM}\right)$, while it is reasonably potent in inhibiting the same mode in the guinea pig $\left(\mathrm{IC}_{50}=355 \mathrm{~nm}\right)$, as well as the two other modes (heat and CAP) in both species (Table 1). This hypothesis was confirmed. In guinea pigs, CPZ (65.5 $\mu \mathrm{mol} / \mathrm{kg}$, i.v.) increased the abdominal temperature by $0.5 \pm 0.1^{\circ} \mathrm{C}(p<0.005)$ (Fig. $\left.2 A\right)$, whereas in rats, it neither changed $T_{\mathrm{c}}$ nor caused tail skin vasoconstriction, the first autonomic cold-defense effector to be recruited in a response (Fig. $2 B$ ).

\section{Mathematical modeling: contributions of different TRPV1} activation modes to TRPV1 antagonist-induced hyperthermia Two sets of data were fit into the mathematical model: with and without JYL1421, the compound that caused hypothermia. If one assumes that the same TRPV1-dependent mechanism underlies both the hyperthermic and hypothermic effects of TRPV 1 antagonists, then the JYL1421 data should be included in the analysis. Such a hypothetical common mechanism may take place if, e.g., deep body temperature continuously increases or decreases depending on whether proton activation is inhibited or potentiated. However, the hypothermic and hyperthermic effects may occur via separate mechanisms. For example, lipopolysaccharide-induced fever and hypothermia have distinct biochemical (Steiner et al., 2009) and neural (Almeida et al., 2006) pathways. If one assumes that the mechanism of the hypothermic effect of JYL1421 differs qualitatively from that of the hyperthermic effect of other TRPV1 antagonists, then the data obtained with JYL1421 cannot be used to analyze the hyperthermic effect. Whether TRPV1 antagonist-induced hyperthermia and hypothermia occur via the same or different mechanisms is unknown.
When the same mechanism was assumed, and the JYL1421 data were included in the analysis, the thermoregulatory effect of TRPV1 antagonists was found to be highly sensitive to the extent of TRPV 1 blockade in the proton mode $(0.65 \pm 0.06)$ and nearly insensitive to the blockade in either the CAP mode $(-0.01 \pm$ $0.00)$ or heat mode $(0.01 \pm 0.00)$. All the sensitivity values (even those close to 0$)$ differed significantly from $0(p<0.002)$ and from each other $(p<0.001)$. More than $81 \%$ of the statistical variance of the hyperthermic response $H$ was determined by the proton mode, whereas both the heat mode and the CAP mode accounted for $1 \%$ each, and $16 \%$ remained unaccounted by the model. The $r^{2}$ statistic (0.84) indicated a high quality of data fitting. A graphical abstract of the modeling study is presented in Figure 3.

When different mechanisms were assumed, and the JYL1421 data were excluded, the hyperthermic effect showed a high sensitivity to the extent of TRPV1 blockade in the proton mode $(0.43 \pm 0.08)$, a moderate sensitivity in the CAP mode $(0.34 \pm$ $0.06)$, and no sensitivity in the heat mode $(0.00 \pm 0.00)$. The sensitivity values for the proton and CAP modes differed both from 0 and from the sensitivity in the heat mode $(p<0.005)$, but not from each other. The proton mode accounted for $45 \%$ of the hyperthermic response variance, the CAP mode for 35\%, and the heat mode for $0 \%$, whereas $20 \%$ of the variance was unaccounted by the model (Fig. 3). The quality of data fitting remained high $\left(r^{2}=0.80\right)$.

\section{Discussion}

The first finding of this study is that the blockade of TRPV1 activation in the heat mode does not contribute to the development of TRPV1 antagonist-induced hyperthermia. Indeed, the graphical analysis has found no correspondence between the potency of an antagonist to cause hyperthermia and its potency to block the heat mode (Fig. $1 A$ ), whereas the mathematical model has shown that the contribution of the blockade of the heat mode to the hyperthermic effect is $\sim 0$ (Fig. 3 ). That the heat mode is uninvolved agrees with our study with AMG0347, in which no positive correlation was found between the body temperature at the time of drug administration and the magnitude of the hyperthermic response, thus suggesting that TRPV1 channels that mediate AMG0347-induced hyperthermia are activated by nonthermal signals (Steiner et al., 2007).

Our second finding is that the potency of TRPV1 antagonists to cause hyperthermia relates most closely to their potency to block TRPV1 activation by protons. The importance of the proton mode was proposed earlier, based on an observation that AMG8562, an antagonist that potentiates TRPV1 activation by protons, did not cause hyperthermia in rats (Lehto et al., 2008). The present work determines the quantitative contribution of the proton mode. The sensitivity of the hyperthermic response to the blockade in this mode is the highest (0.43-0.65), regardless of which set of data is fit into the model, and it accounts for $45-81 \%$ of the variance of the thermoregulatory effect of TRPV 1 antagonists (Fig. 3). Both the graphical (Fig. $1 B$ ) and comparative (Fig. 2) analyses confirm the principal role of the proton mode. Guinea pigs, the species in which CPZ blocks TRPV1 activation by protons, are more sensitive to the hyperthermic effect of this antagonist than rats, the species in which $\mathrm{CPZ}$ does not block the proton mode.

Our third finding is that the blockade of the CAP mode either does not contribute to TRPV1 antagonist-induced hyperthermia or makes only a limited contribution. Depending on which dataset is fit into the model, the sensitivity of the hyperthermic response to the blockade of this mode is either negligible or moderate (Fig. 3). 

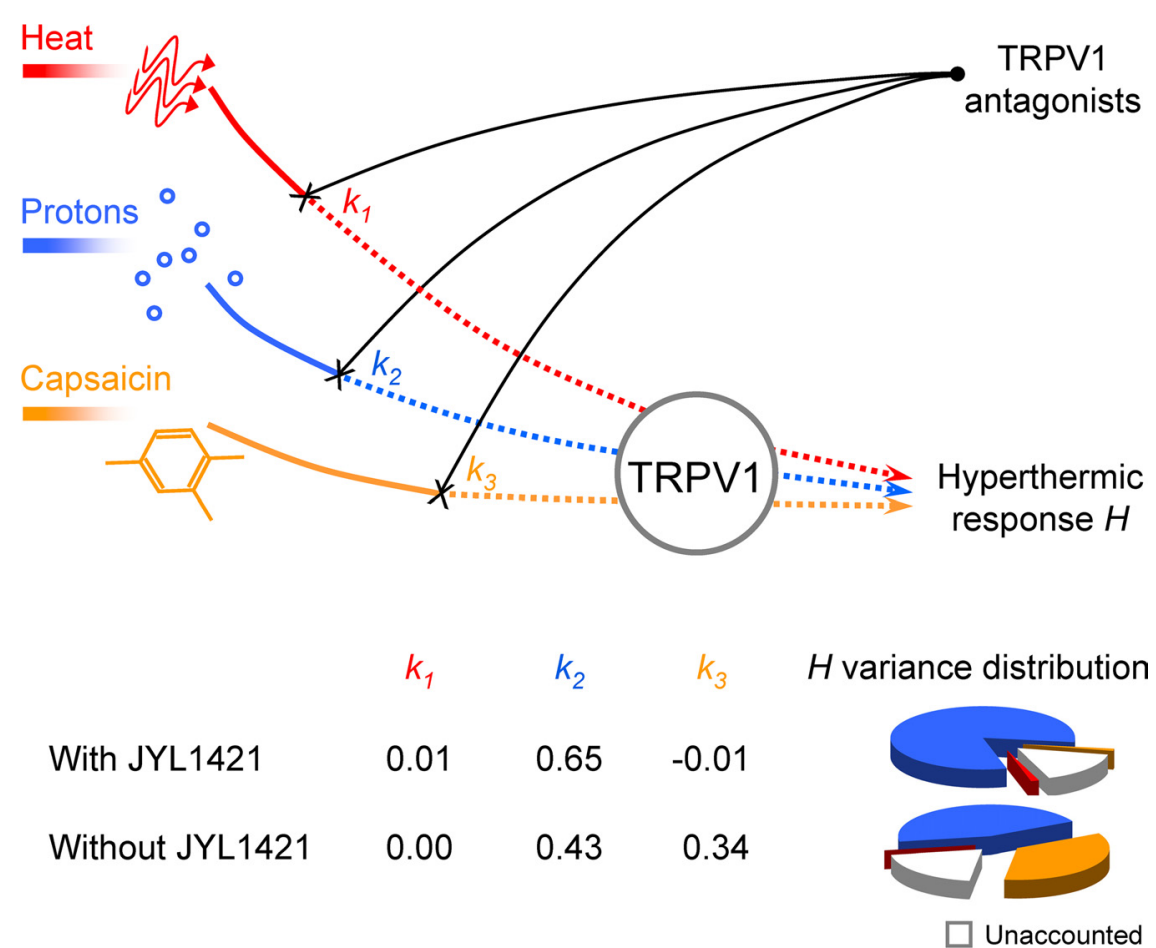

Figure 3. Contribution of different modes of TRPV1 activation to the development of TRPV1 antagonist-induced hyperthermia. Signals activating TRPV1 in the heat mode (red line), proton mode (blue line), and (AP mode (orange line) are differentially blocked by TRPV1 antagonists (black lines) to cause the hyperthermic response $H$. The $k_{1}, k_{2}$, and $k_{3}$ values are relative sensitivities of $H$ to the extent of TRPV1 blockade in the heat, proton, and CAP modes, respectively. The pie charts show relative contributions of each mode (and of factors unaccounted by the model) to the variance of $H$. Because two sets of data were fit into the model (with JYL1421 and without JYL1421), two sets of $k$ values and two pie charts are shown.

Based on these three findings, the hyperthermic response to TRPV1 antagonists is triggered by the blockade of the proton mode of TRPV1 activation, either alone or together with the CAP mode. Hence, it is likely that the body temperature is tonically suppressed by a low tissue $\mathrm{pH}$, either alone or together with endogenous ligands. Because TRPV1 antagonists cause hyperthermia by acting within the abdomen (Steiner et al., 2007; McGaraughty et al., 2009), it is of interest that two major intra-abdominal organs, the stomach and colon, have an acidic environment (Holzer, 2007). TRPV1 channels are abundant on dorsal-root and nodose afferents innervating these organs and serve there as acidity sensors (Holzer, 2007; Sugiura et al., 2007). By acting on two different extracellular residues, the $\mathrm{pH}$ has a dual effect on the TRPV1 channel: at a low $\mathrm{pH}(<6)$, protons act as agonists and open the channel; at a higher $\mathrm{pH}(6-7)$, protons lower the threshold for TRPV1 activation (Jordt et al., 2000). One of these ligands, oleoylethanolamide (OEA), is present in the intestinal wall at concentrations comparable with its $\mathrm{EC}_{50}$ against TRPV1 (Fu et al., 2003). At least some responses to OEA are ablated in CAPdesensitized animals, thus suggesting an action on TRPV1expressing afferent fibers (Rodríguez de Fonseca et al., 2001). OEA also causes hypothermia in mice (Watanabe et al., 1999). Although TRPV1 activation by protons alone or in conjunction with lipid mediators is a plausible scenario, other scenarios are also possible. For example, multiple cationic stimuli (e.g.) $\mathrm{Ca}^{2+}$, $\mathrm{Mg}^{2+}, \mathrm{Na}^{+}$, and polycations such as spermine) can directly gate or sensitize the TRPV1 channel by interacting with the same sites in the pore loop domain that are the targets for protons (Ahern et al., 2005, 2006).

Potential TRPV1 antagonists are routinely screened by pharmaceutical companies in three main modes (heat, proton, and CAP), and the corresponding $\mathrm{IC}_{50}$ data are available for a large number of compounds (see, e.g., Table 1). Hence, the goal of the present study was to find a general rule for identifying hyperthermia-free TRPV1 antagonists based on standard in vitro tests in the three modes. The TRPV1 channel can also be activated independently of the three main modes, e.g., by ammonia or intracellular alkalization (Dhaka et al., 2009). The potentiation effect of modest acidity on vanilloid-evoked TRPV1 activation also has a different substrate than the activation effect exerted by high concentrations of protons (Jordt et al., 2000). How the potency of TRPV1 antagonists to block these, less studied, modes correlates with the potency to cause hyperthermia remains unknown.

As for the main modes of TRPV1 activation, our study shows that hyperthermia-free TRPV1 antagonists do not block the proton mode, even if they potently block the heat mode, and that decreasing the potency to block the CAP mode of TRPV1 activation may further decrease the potency to cause hyperthermia. This profile identified is similar to the profile of $\mathrm{CPZ}$, the first relatively selective TRPV1 antagonist synthesized, against the rat or murine TRPV1 channel (Table 1). Indeed, although CPZ has been used extensively in thermoregulation studies in rats and mice (Dogan et al., 2004; Shimizu et al., 2005), it has not been reported to cause hyperthermia. On the other hand, analgesic efficacy for $\mathrm{CPZ}$ has been demonstrated in rat and murine models of chemically induced hyperalgesia, inflammatory pain, and neurogenic inflammation (Walker et al., 2003; Dinis et al., 2004; Hutter et al., 2005), even though CPZ did not cause analgesia in some rat models in the study by Walker et al. (2003).

Because eliminating the hyperthermic side effect requires a drastic decrease in the potency to block TRPV1 activation by protons and possibly by CAP, it is important to determine under which conditions the blockade of thermal and, to a lesser extent, chemical activation of TRPV1 provides sufficient therapeutic benefits. Such conditions are likely to entail abnormal thermal stimulation (e.g., due to the perfusion of the skin with the warm blood redirected from the body core, as seen in hot flushes) or thermal hyperalgesia (which is prominent in burns, frostbites, and peripheral neuropathies). Involvement of TRPV1 channels in some of these conditions has been demonstrated (Walker et al., 2003; Bölcskei et al., 2005). The significance of the present work, however, is limited to identifying the pharmacological profile of hyperthermia-free TRPV1 antagonists. For which conditions to use them is a subject of future research.

\section{References}

Ahern GP, Brooks IM, Miyares RL, Wang XB (2005) Extracellular cations sensitize and gate capsaicin receptor TRPV1 modulating pain signaling. J Neurosci 25:5109-5116.

Ahern GP, Wang X, Miyares RL (2006) Polyamines are potent ligands for the capsaicin receptor TRPV1. J Biol Chem 281:8991-8995. 
Almeida MC, Steiner AA, Branco LG, Romanovsky AA (2006) Neural substrate of cold-seeking behavior in endotoxin shock. PLoS One 1:e1.

Bölcskei K, Helyes Z, Szabó A, Sándor K, Elekes K, Németh J, Almási R, Pintér E, Petho G, Szolcsányi J (2005) Investigation of the role of TRPV1 receptors in acute and chronic nociceptive processes using gene-deficient mice. Pain 117:368-376.

Caterina MJ, Schumacher MA, Tominaga M, Rosen TA, Levine JD, Julius D (1997) The capsaicin receptor: a heat-activated ion channel in the pain pathway. Nature 389:816-824.

Dhaka A, Uzzell V, Dubin AE, Mathur J, Petrus M, Bandell M, Patapoutian A (2009) TRPV1 is activated by both acidic and basic pH. J Neurosci 29:153-158.

Dinis P, Charrua A, Avelino A, Yaqoob M, Bevan S, Nagy I, Cruz F (2004) Anandamide-evoked activation of vanilloid receptor 1 contributes to the development of bladder hyperreflexia and nociceptive transmission to spinal dorsal horn neurons in cystitis. J Neurosci 24:11253-11263.

Dogan MD, Patel S, Rudaya AY, Steiner AA, Székely M, Romanovsky AA (2004) Lipopolysaccharide fever is initiated via a capsaicin-sensitive mechanism independent of the subtype-1 vanilloid receptor. Br J Pharmacol 143:1023-1032.

Fu J, Gaetani S, Oveisi F, Lo Verme J, Serrano A, Rodríguez De Fonseca F, Rosengarth A, Luecke H, Di Giacomo B, Tarzia G, Piomelli D (2003) Oleylethanolamide regulates feeding and body weight through activation of the nuclear receptor PPAR-alpha. Nature 425:90-93.

Gavva NR, Tamir R, Qu Y, Klionsky L, Zhang TJ, Immke D, Wang J, Zhu D, Vanderah TW, Porreca F, Doherty EM, Norman MH, Wild KD, Bannon AW, Louis JC, Treanor JJ (2005) AMG 9810 [(E)-3-(4-t-butylphenyl)$N$-(2,3-dihydrobenzo[ $b][1,4]$ dioxin-6-yl)acrylamide], a novel vanilloid receptor 1 (TRPV1) antagonist with antihyperalgesic properties. J Pharmacol Exp Ther 313:474-484.

Gavva NR, Bannon AW, Surapaneni S, Hovland DN Jr, Lehto SG, Gore A, Juan T, Deng H, Han B, Klionsky L, Kuang R, Le A, Tamir R, Wang J, Youngblood B, Zhu D, Norman MH, Magal E, Treanor JJS, Louis JC (2007a) The vanilloid receptor TRPV1 is tonically activated in vivo and involved in body temperature regulation. J Neurosci 27:3366-3374.

Gavva NR, Bannon AW, Hovland DN Jr, Lehto SG, Klionsky L, Surapaneni S, Immke DC, Henley C, Arik L, Bak A, Davis J, Ernst N, Hever G, Kuang R, Shi L, Tamir R, Wang J, Wang W, Zajic G, Zhu D, et al. (2007b) Repeated administration of vanilloid receptor TRPV1 antagonists attenuates hyperthermia elicited by TRPV1 blockade. J Pharmacol Exp Ther 323:128-137.

Gavva NR, Treanor JJ, Garami A, Fang L, Surapaneni S, Akrami A, Alvarez F, Bak A, Darling M, Gore A, Jang GR, Kesslak JP, Ni L, Norman MH, Palluconi G, Rose MJ, Salfi M, Tan E, Romanovsky AA, Banfield C, et al. (2008) Pharmacological blockade of the vanilloid receptor TRPV1 elicits marked hyperthermia in humans. Pain 136:202-210.

Ghilardi JR, Röhrich H, Lindsay TH, Sevcik MA, Schwei MJ, Kubota K, Halvorson KG, Poblete J, Chaplan SR, Dubin AE, Carruthers NI, Swanson D, Kuskowski M, Flores CM, Julius D, Mantyh PW (2005) Selective blockade of the capsaicin receptor TRPV1 attenuates bone cancer pain. J Neurosci 25:3126-3131.

Holzer P (2007) Taste receptors in the gastrointestinal tract. V. Acid sensing in the gastrointestinal tract. Am J Physiol Gastrointest Liver Physiol 292:G699-G705.

Honore P, Chandran P, Hernandez G, Gauvin DM, Mikusa JP, Zhong C, Joshi SK, Ghilardi JR, Sevcik MA, Fryer RM, Segreti JA, Banfor PN, Marsh K, Neelands T, Bayburt E, Daanen JF, Gomtsyan A, Lee CH, Kort ME, Reilly RM, et al. (2009) Repeated dosing of ABT-102, a potent and selective TRPV1 antagonist, enhances TRPV1-mediated analgesic activity in rodents, but attenuates antagonist-induced hyperthermia. Pain 142:27-35.

Hutter MM, Wick EC, Day AL, Maa J, Zerega EC, Richmond AC, Jordan TH, Grady EF, Mulvihill SJ, Bunnett NW, Kirkwood KS (2005) Transient receptor potential vanilloid (TRPV-1) promotes neurogenic inflamma- tion in the pancreas via activation of the neurokinin-1 receptor (NK-1R). Pancreas 30:260-265.

Jordt SE, Tominaga M, Julius D (2000) Acid potentiation of the capsaicin receptor determined by a key extracellular site. Proc Natl Acad Sci U S A 97:8134-8139.

Lehto SG, Tamir R, Deng H, Klionsky L, Kuang R, Le A, Lee D, Louis JC, Magal E, Manning BH, Rubino J, Surapaneni S, Tamayo N, Wang T, Wang J, Wang J, Wang W, Youngblood B, Zhang M, Zhu D, et al. (2008) Antihyperalgesic effects of $(R, E)-N$-(2-hydroxy-2,3-dihydro- $1 H$-inden4-yl)-3-(2-(piperidin-1-yl)-4-(trifluoromethyl)phenyl)-acrylamide (AMG8562), a novel transient receptor potential vanilloid type 1 modulator that does not cause hyperthermia in rats. J Pharmacol Exp Ther 326:218-229.

McGaraughty S, Segreti JA, Fryer RM, Brown BS, Faltynek CR, Kym PR (2009) Antagonism of TRPV1 receptors indirectly modulates activity of thermoregulatory neurons in the medial preoptic area of rats. Brain Res 1268:58-67.

Rodríguez de Fonseca F, Navarro M, Gómez R, Escuredo L, Nava F, Fu J, Murillo-Rodríguez E, Giuffrida A, LoVerme J, Gaetani S, Kathuria S, Gall C, Piomelli D (2001) An anorexic lipid mediator regulated by feeding. Nature 414:209-212.

Romanovsky AA, Ivanov AI, Shimansky YP (2002) Ambient temperature for experiments in rats: a new method for determining the zone of thermal neutrality. J Appl Physiol 92:2667-2679.

Romanovsky AA, Almeida MC, Garami A, Steiner AA, Norman MH, Morrison SF, Nakamura K, Burmeister JJ, Nucci TB (2009) The transient receptor potential vanilloid-1 channel in thermoregulation: a thermosensor it is not. Pharmacol Rev 61:228-261.

Rudaya AY, Steiner AA, Robbins JR, Dragic AS, Romanovsky AA (2005) Thermoregulatory responses to lipopolysaccharide in the mouse: dependence on the dose and ambient temperature. Am J Physiol Regul Integr Comp Physiol 289:R1244-R1252.

Savidge J, Davis C, Shah K, Colley S, Phillips E, Ranasinghe S, Winter J, Kotsonis P, Rang H, McIntyre P (2002) Cloning and functional characterization of the guinea pig vanilloid receptor 1 . Neuropharmacology 43:450-456.

Shimizu I, Iida T, Horiuchi N, Caterina MJ (2005) 5-Iodoresiniferatoxin evokes hypothermia in mice and is a partial transient receptor potential vanilloid 1 agonist in vitro. J Pharmacol Exp Ther 314:1378-1385.

Steiner AA, Turek VF, Almeida MC, Burmeister JJ, Oliveira DL, Roberts JL, Bannon AW, Norman MH, Louis JC, Treanor JJ, Gavva NR, Romanovsky AA (2007) Nonthermal activation of transient receptor potential vanilloid-1 channels in abdominal viscera tonically inhibits autonomic cold-defense effectors. J Neurosci 27:7459-7468.

Steiner AA, Hunter JC, Phipps SM, Nucci TB, Oliveira DL, Roberts JL, Scheck AC, Simmons DL, Romanovsky AA (2009) Cyclooxygenase-1 or -2which one mediates lipopolysaccharide-induced hypothermia? Am J Physiol Regul Integr Comp Physiol 297:R485-R494.

Sugiura T, Bielefeldt K, Gebhart GF (2007) Mouse colon sensory neurons detect extracellular acidosis via TRPV1. Am J Physiol Cell Physiol 292:C1768-C1774.

Suh YG, Lee YS, Min KH, Park OH, Seung HS, Kim HD, Park HG, Choi J, Lee J, Kang SW, Oh UT, Koo JY, Joo YH, Kim SY, Kim JK, Park YH (2003) Novel non-vanilloid VR1 antagonist of high analgesic effects and its structural requirement for VR1 antagonistic effects. Bioorg Med Chem Lett 13:4389-4393.

Walker KM, Urban L, Medhurst SJ, Patel S, Panesar M, Fox AJ, McIntyre P (2003) The VR1 antagonist capsazepine reverses mechanical hyperalgesia in models of inflammatory and neuropathic pain. J Pharmacol Exp Ther 304:56-62.

Watanabe K, Matsunaga T, Nakamura S, Kimura T, Ho IK, Yoshimura H, Yamamoto I (1999) Pharmacological effects in mice of anandamide and its related fatty acid ethanolamides, and enhancement of cataleptogenic effect of anandamide by phenylmethylsulfonyl fluoride. Biol Pharm Bull 22:366-370. 